\title{
Long non-coding RNA nuclear paraspeckle assembly transcript 1 interacts with microRNA-107 to modulate breast cancer growth and metastasis by targeting carnitine palmitoyltransferase-1
}

\author{
YIQUAN XIONG* ${ }^{*}$ ZEMING LIU*, ZHI LI, SHUNTAO WANG, NA SHEN, YUE XIN and TAO HUANG \\ Department of Breast and Thyroid Surgery, Union Hospital, Tongji Medical College, \\ Huazhong University of Science and Technology, Wuhan, Hubei 430022, P.R. China
}

Received February 8, 2018; Accepted February 28, 2019

DOI: $10.3892 /$ ijo.2019.4869

\begin{abstract}
Previous studies revealed that the long non-coding RNA nuclear paraspeckle assembly transcript 1 (NEAT1) exhibits abnormal expression in numerous cancer types, including breast cancer (BC); however, the regulatory mechanism of NEAT 1 in BC remains unclear. In the present study, the effect of NEAT1 on the progression of BC and its regulation mechanism was investigated. The expression levels of NEAT1 and microRNA-107 (miR-107) in BC cells were analyzed using the reverse transcription-quantitative polymerase chain reaction (RT-qPCR). NEAT1 was knocked down in BC cells, and mimics-miR-107 or inhibitor-miR-107 were transfected into BC cells. Subsequently, cell proliferation, invasion and migration, apoptosis and cell cycle distribution were determined. The regulatory mechanism of NEAT1, miR-107 and carnitine palmitoyltransferase-1 (CPT1A) was analyzed using a luciferase reporter assay system, western blotting and RT-qPCR. NEAT1 expression was increased in BC cells, whereas miR-107 expression was decreased, compared with normal mammary gland cells. NEAT1 promoted the progression of BC cells through inhibiting apoptosis-associated genes and promoting cell cycle- and invasion-associated gene expression, whereas miR-107 served the opposite function. Furthermore, NEAT1 promoted the expression of CPT1A, which was mediated by miR-107. The results of the present study indicate that NEAT1 promotes the expression of CPT1A by inhibiting miR-107 to improve the progression of BC cells; therefore, NEAT1 is a potential therapeutic target of BC.
\end{abstract}

Correspondence to: Dr Tao Huang, Department of Breast and Thyroid Surgery, Union Hospital, Tongji Medical College, Huazhong University of Science and Technology, 1277 Jiefang Road, Wuhan, Hubei 430022, P.R. China

E-mail: huangtao180117@sina.com

${ }^{*}$ Contributed equally

Key words: breast cancer, nuclear paraspeckle assembly transcript 1, microRNA-107, carnitine palmitoyltransferase-1

\section{Introduction}

Breast cancer (BC) is a malignant tumor that occurs in the epithelial tissue of the mammary gland and was the most common cancer type among women globally (1). In China, in $2015,272,400$ novel BC cases were identified with a mortality toll of 70,700 in 2015 (2). In the USA, in 2016, the number of novel cases and mortalities of BC were 249,260 and 40,890, respectively (3). Although the combined treatment of surgery, radiotherapy, chemotherapy, endocrine therapy and targeted therapy has achieved good clinical results, recurrence and metastasis remain the primary factors affecting survival (4). Non-coding RNAs, which do not encode protein, may be classified as short non-coding RNAs, including microRNAs (miRNAs), and long non-coding RNAs (lncRNAs), for example, HOTAIR, H19 and MALAT1 have been widely studied (5). These RNAs bind to specific sequences to degrade the transcription of target genes (5). Previous studies confirmed that lncRNAs serve important functions in numerous biological processes, including guiding chromosome remodeling and regulating miRNAs (6-9). Compared with normal tissues, cancer tissues exhibit abnormal expression of lncRNAs (10). Increasing evidence demonstrated that a high level of the lncRNA nuclear paraspeckle assembly transcript 1 (NEAT1) is associated with unfavorable prognosis in BC $(11,12)$.

NEAT1 is located at nuclear paraspeckles to form and maintain their structure $(13,14)$. The stabilization of paraspeckles can interrupt mRNA, which is retained in paraspeckles and translated into protein, regulating the expression of target genes accurately and rapidly $(15,16)$. NEAT1 is upregulated prominently in hypoxia-regulated BC cells (17). The transcription of NEAT1 is primarily regulated by hypoxia-inducible factor-2, and the overexpression of NEAT1 can accelerate cell proliferation and inhibit apoptosis (18). The prognosis of patients with BC with high expression of NEAT1 is significantly decreased, compared with patients with low NEAT1 expression (19). Further studies indicated that NEAT1 combines with miR-107 and downregulates its expression level to promote the progression of numerous human cancer types, including glioma and laryngeal squamous cell cancer $(20,21)$. A number of studies have identified that miR-107 serves a significant function in the development and progression of 
tumors. This miRNA acts as a tumor suppressor molecule whose expression is inhibited in the majority of cancer types, including glioma (20), laryngeal squamous cell cancer (21), pancreatic carcinoma (22), colon carcinoma (23) and BC (24).

Carnitine palmitoyltransferase-1 (CPT1) is a key regulatory and rate-limiting enzyme of long-chain fatty acids for $\beta$-oxidation $(25,26)$. This protein is located on the outer membrane of mitochondria through the transmembrane domain and catalyzes the formation of acylcarnitine, which is then transferred to the mitochondrial inner membrane and $\beta$-oxidized by CPT2 (27). CPT1A, a subtype of the CPT1 gene family, is expressed in all tissue types except skeletal muscle cells and brown adipose cells (27). The proliferation of tumors requires a large amount of raw material and energy, and the abnormality of lipid synthesis and catabolism are classical features of tumor cells (28). CPT1A is highly expressed in ovarian cancer, prostate cancer and other types of cancer, and it serves a key function in promoting tumor cell proliferation and metastasis $(29,30)$.

In $\mathrm{BC}, \mathrm{CPT} 1 \mathrm{~A}$ is associated with histone deacetylase activity to regulate cell survival, cell death escape and invasion of MCF-7, SK-BR3 and MDA-MB-231 cell lines (31). miR-107, an inhibitor of $\beta$-oxidation by downregulating the expression of CTP1A and other associated genes (32), can promote lipid accumulation (33) and inhibit tumor progression (20-24). However, the inhibitory mechanism of miR-107 to CPT1A is unclear. Previous studies demonstrated that NEAT1 downregulates the expression level of miR-107 to promote the progression of numerous human cancer types, including glioma and laryngeal squamous cell cancer $(20,21)$, but whether this inhibitory mechanism is applicable to BC requires confirmation.

In the present study, first, the expression of NEAT1 and miR-107 in BC cells was determined using the reverse transcription-quantitative polymerase chain reaction (RT-qPCR), and it was identified that the lncRNA NEAT1 was upregulated and that miR-107 was downregulated and associated with the progression of BC. Subsequently, the function of NEAT1 and miR-107 in BC cells was investigated. It was identified that knockdown of NEAT1 or transfection of mimics-miR-107 inhibited the proliferation and invasion of BC cells. Furthermore, it was identified that NEAT1 upregulated CPT1A through inhibiting the expression of miR-107. These results provide evidence that $\mathrm{BC}$ is promoted by the NEAT1-miR-107-CPT1A regulatory network.

\section{Materials and methods}

Cell and reagents. Human mammary epithelial cell lines MCF-10A (cat. no. ATCC ${ }^{\circledR}$ CRL-10317 ${ }^{\mathrm{TM}}$ ), BC lines MCF-7 (cat. no. ATCC ${ }^{\circledR}$ HTB-22 ${ }^{\mathrm{TM}}$ ), MDA-MB-231 (cat. no. ATCC ${ }^{\circledR}$ HTB-26 $^{\mathrm{TM}}$ ) were and 293 (cat. no. ATCC $^{\circledR}$ CRL-1573 ${ }^{\mathrm{TM}}$ ) purchased from the American Type Culture Collection (Manassas, VA, USA). These cells were cultured in Dulbecco's modified Eagle's medium (DMEM; cat. no. 11965-084; Gibco; Thermo Fisher Scientific, Inc., Waltham, MA, USA) at $37^{\circ} \mathrm{C}$ in humidified atmosphere of $5 \% \mathrm{CO}_{2}$. Lentivirus vector pLKO.1 (cat. no. E365), and packaging plasmids psPAX2 (cat. no. E366) and pMD2G (cat. no. E367) were purchased from AtaGenix Laboratories
(Wuhan, China). The pcDNA3.1 plasmid (cat. no. V00454) was purchased from Fenghui Bio (Changsha, China). TRIzol ${ }^{\circledR}$ (cat. no. 15596018), ThermoScript ${ }^{\mathrm{TM}}$ RT-PCR System (cat. no. K1691), Lipofectamine ${ }^{\circledR} 2000$ (cat. no. 11668019), RPMI-1640 (cat. no. 11875085) and fetal bovine serum (FBS; cat. no. 10099141) were purchased from Invitrogen (Thermo Fisher Scientific, Inc.). iTaq ${ }^{\mathrm{TM}}$ Universal SYBR $^{\circledR}$ Green supermix (cat. no. 172-5121) and LumiPico ${ }^{\circledR}$ Enhanced Chemiluminescent (ECL) reagent (cat. no. 1705060) were purchased from Bio-Rad Laboratories, Inc. (Hercules, CA, USA). Cell Proliferation kit I (MTT; cat. no. 11465007001) was purchased from Sigma-Aldrich; Merck KGaA (Darmstadt, Germany). Anti-B-cell lymphoma 2-associated agonist of cell death (BAD; cat. no. ab32445), anti-caspase 9 (CASP9; cat. no. ab32539), anti-collagen type XVII a 1 (COL18A1; cat. no. ab64569), anti-metallopeptidase inhibitor 1 (TIMP-1; cat. no. ab61224), anti-platelet-derived growth factor subunit A (PDGF-A; cat. no. ab38562), anti-serpin family B member 2 (SERPINB2; cat. no. ab47742), anti-cyclin D1 (cat. no. ab134175), anti-cyclin-dependent kinase 4 (CDK4; cat. no. ab108357) and horseradish peroxidase-conjugated goat anti-rabbit immunoglobulin G (cat. ab205718) antibodies were purchased from Abcam (Cambridge, MA, USA). Short hairpin RNA against NEAT1 (sh-NEAT1), sh-negative control (NC), mimics-miR-107 (sense: 5'-ACUAUCGGG ACAUGUUACGACGA-3'; antisense: 5'-UCGUCGUAACAU GUCCCGAUAGUUU-3') and inhibitor-miR-107 (5'-UCG UCGUAACAUGUCCCGAUAGU-3') were synthetized by Shanghai GenePharma Co., Ltd. (Shanghai, China). The Dual Luciferase Reporter assay system (cat. no. E1910) was purchased from Promega Corporation (Madison, WI, USA). Cells were analyzed for DNA content by flow cytometry (FACSCalibur; BD Biosciences, Franklin Lakes, NJ, USA).

Transient transfection. Lipofectamine $2000(2 \mu \mathrm{l})$ was diluted with $100 \mu \mathrm{l}$ Opti-MEM at 1:50 (both Gibco; Thermo Fisher Scientific, Inc.) and incubated for $5 \mathrm{~min}$ at room temperature. pcDNA3.1-NEAT1 plasmid (1 $\mu \mathrm{g}$; ratio, 1:50), $2 \mu \mathrm{g}$ mimics-miRNA or inhibitor-miRNA (both final concentration, $100 \mathrm{nM}$ ) was diluted in $50 \mu \mathrm{l}$ Opti-MEM. The diluted Lipofectamine 2000 and pcDNA3.1-NEAT1 plasmid, mimics-miRNA or inhibitor-miRNA were mixed $(1: 1)$ and incubated at room temperature for $20 \mathrm{~min}$. Finally, the mixture was added to MCF-7 and MDA-MB-231 for culture for between 24 and $48 \mathrm{~h}$ at $37^{\circ} \mathrm{C}$.

sh-NEAT1 was cloned into the lentivirus vector pLKO.1 and termed pLKO.1-shNEAT1. MCF-7 and MDA-MB-231 cells were inoculated into the 6-well plate until the density reached $80 \%$ confluence. pLKO.1-shNEAT1, psPAX2 and pMD2G were mixed at a ratio of 5:3:2 in Opti-MEM.

293 cells were inoculated in six-well plates using DMEM supplemented with $10 \% \mathrm{FBS}, 1 \%$ penicillin $(100 \mathrm{U} / \mathrm{ml})$ and streptomycin $(100 \mathrm{U} / \mathrm{ml})$ at $37^{\circ} \mathrm{C}$ until the density reached $90 \%$ confluence. The pLKO.1-shNEAT1 plasmid or pLKO.1-shNC was then transfected into 293 cells with psPAX2 packaging plasmid and pMD2G envelope plasmid by Lipofectamine 2000 to produce shRNA-containing lentivirus. The infection efficiency was detected under a fluorescence microscope (at a magnification of $\times 200$ ) according to the green fluorescent protein expression level. Following incubation for $20 \mathrm{~min}$ with 
Lipofectamine 2000 at room temperature, the mixture was added to the cells and cultured for $8 \mathrm{~h}$ at $37^{\circ} \mathrm{C}$. Culture medium was replaced with fresh DMEM supplemented with $10 \% \mathrm{FBS}$, $1 \%$ penicillin and streptomycin for virus packaging. After $24 \mathrm{~h}$, the lentiviral particles in the supernatant were harvested and filtered by centrifugation at $500 \mathrm{x}$ for $10 \mathrm{~min}$ at $4{ }^{\circ} \mathrm{C}$.

MCF-7 and MDA-MB-231 cells were cultured with $1.5 \mathrm{ml}$ RPMI-1640 to $50 \%$ confluence in 6 -well plates at $37^{\circ} \mathrm{C}$. Subsequently, $0.5 \mathrm{ml}$ virus was added into each well for infection. After $24 \mathrm{~h}$, the medium containing the virus was replaced with a fresh RPMI-1640 medium and the cells were cultured for another $48 \mathrm{~h}$ at $37^{\circ} \mathrm{C}$. The infection efficiency was detected under a fluorescence microscope (at a magnification of $\mathrm{x} 200$ ) according to the green fluorescent protein expression level.

RNA extraction and RT-PCR. MCF-7 and MDA-MB-231 cells were collected and lysed with TRIzol reagent. Total RNA was extracted with TRIzol and was precipitated using $0.5 \mathrm{ml}$ of 95\% isopropanol, followed by washing once with $75 \%$ ethanol. Finally, the total RNA was dissolved in RNase-free water. Following RNA extraction, cDNA was synthetized using the ThermoScript ${ }^{\mathrm{TM}}$ RT-PCR system according to the manufacturer's protocol. iTaq Universal SYBR Green supermix was used for qPCR according to the manufacturer's protocol. cDNA was then amplified using the following cycling conditions: One initial PCR activation step at $95^{\circ} \mathrm{C}$ for 15 min followed by 40 cycles of denaturation at $94^{\circ} \mathrm{C}$ for $15 \mathrm{sec}$, annealing at $53^{\circ} \mathrm{C}$ for $30 \mathrm{sec}$, and elongation at $72^{\circ} \mathrm{C}$ for $30 \mathrm{sec}$. The U6 (for miR-107) and GAPDH (for NEAT1 and CPT1A) were used as internal controls. $\mathrm{Cq}$ values were used for quantification using a previously described protocol (34). Primers were as follows: NEAT1 forward, 5'-CTTCCTCCCTTTAACTTATCCATT CAC-3'; reverse, 5'-CTCTTCCTCCACCATTACCAACAA TAC-3'; miR-107 forward, 5'-ATGATGAGCAGCATTGTA CAGG-3'; reverse, 5'-GCAGGGTCCGAGGTATTC-3'; CPT1A forward, 5'-TTCAGTTCACGGTCACTCCG-3'; reverse 5'-TGA CCACGTTCTTCGTCTGG-3'; GAPDH forward, 5'-TGCACC ACCAACTGCTTAGC-3'; reverse, 5'-GGCATGGACTGT GGTCATGAG-3'; U6 forward, 5'-CTCGCTTCGGCAGCA CA-3'; reverse, 5'-AACGCTTCACGAATTTGCGT-3'.

MTT assay. MCF-7 and MDA-MB-231 cells were plated in 96-well plates at the density of 10,000 cells per well, and cultured at $37^{\circ} \mathrm{C}$ for $72 \mathrm{~h}$ in an atmosphere containing $5 \%$ $\mathrm{CO}_{2}$. Cells that were cultured for $0,24,48$ and $72 \mathrm{~h}$ were analyzed using a Cell Proliferation kit I according to the manufacturer's protocol. Following culture, MTT solution was added to cells and incubated for another $4 \mathrm{~h}$ at $37^{\circ} \mathrm{C}$. Subsequently, the medium was removed, and $200 \mu \mathrm{l}$ dimethyl sulfoxide (Beyotime Institute of Biotechnology, Haimen, China) was added to each well to dissolve the formazan crystals. The proliferation of cells was measured using a Universal microplate spectrophotometer at $550 \mathrm{~nm}$.

Wound-healing assay. MCF-7 and MDA-MB-231 cells were plated on a 6-well plate and were cultured in RPMI-1640 supplemented with $10 \% \mathrm{FBS}, 1 \%$ penicillin and streptomycin at $37^{\circ} \mathrm{C}$ until reaching $90 \%$ confluence. Cells were scraped off each well at a width of $1 \mathrm{~mm}$ using 1-ml Labtip pipette tips and debris was washed with PBS three times. Subsequently, the cells were cultured with fresh RPMI-1640 at $37^{\circ} \mathrm{C}$ in an atmosphere containing $5 \% \mathrm{CO}_{2}$ for $24 \mathrm{~h}$. The scraped line of each well was viewed under a light microscope (at a magnification of x16) to assay the migration of cells. Furthermore, wound-healing graphs were produced.

Matrigel assay. Transwell chambers were pre-coated with Matrigel at a concentration of $8 \mu \mathrm{g} / \mu \mathrm{l}$ and set on a 24 -well plate. The sublayer of the Transwell chamber was filled with RPMI-1640 containing 10\% FBS. The MCF-7 and MDA-MB-231 cells were digested and suspended in RPMI-1640 medium containing $0.1 \%$ FBS. Subsequently, the suspended cells were inoculated in chambers at a density of $1 \times 10^{5}$ cells $/ \mathrm{ml}$ at $37^{\circ} \mathrm{C}$. After $36 \mathrm{~h}$, the cells and Matrigel that did not pass through the chamber were removed with cotton swabs. The remaining cells were fixed with pre-cold $4 \%$ paraformaldehyde for $30 \mathrm{~min}$ and stained with $0.1 \%$ crystal violet for $30 \mathrm{~min}$ at room temperature. The cells passing through the sublayer of the chamber were observed and enumerated under a light phase-contrast microscope (at a magnification of x100).

Western blotting. Total protein was extracted from MCF-7 and MDA-MB-231 cells with radioimmunoprecipitation assay lysis buffer (Beyotime Institute of Biotechnology) and quantified with a Bicinchoninic Acid kit. Protein samples $(30 \mu \mathrm{g})$ were subjected to SDS-PAGE on $10 \%$ gels. The resolved proteins were transferred onto polyvinylidene fluoride membranes, which were then blocked with $5 \%$ bovine serum albumin (Beyotime Institute of Biotechnology) in TBST at $25^{\circ} \mathrm{C}$ for $1 \mathrm{~h}$. Following incubation with the primary antibodies $(1: 1,000)$ at $4^{\circ} \mathrm{C}$ for overnight and secondary antibodies $(1: 5,000)$ at room temperature for $1 \mathrm{~h}$, membranes were subjected to chromogenic analysis using LumiPico ECL reagent.

Cell cycle analysis by flow cytometry. Cell cycle analysis was determined by Keygen Cell Cycle detection kit (Nanjing KeyGen Biotech Co., Ltd., Nanjing, China). Briefly, MCF-7 and MDA-MB-231 cells were collected and washed with ice-cold PBS three times. Following centrifugation for $5 \mathrm{~min}$ at $1,000 \mathrm{x} \mathrm{g}$ and room temperature, the cells were suspended in ice-cold PBS and fixed in absolute ethanol for $30 \mathrm{~min}$ at $4^{\circ} \mathrm{C}$. Following fixing, the ethanol was removed, and the cells were washed with PBS once to remove residual ethanol. Subsequently, the cells were resuspended in PBS with RNase A and incubated at $37^{\circ} \mathrm{C}$ for $30 \mathrm{~min}$. Finally, the cells were stained with propidium iodide for $30 \mathrm{~min}$ at $37^{\circ} \mathrm{C}$, and the cell cycle distribution was detected by flow cytometry (FACSCalibur) using Cell Quest Pro software version 5.1 (both BD Biosciences).

Luciferase reporter assay. Starbase tool (version 2.0; http://starbase.sysu.edu.cn) and Targetscan tool (version 7.1; http://www.targetscan.org) were used to predict the binding sites of NEAT1 and CPT1A on miR-107. A total of four luciferase reporter plasmids, wild-type (wt)-NEAT1, mutated (mut)-NEAT1, wt-CPT1A and mut-CPT1A, were constructed by Shanghai GenePharma Co., Ltd. pRL-Tk, wt-NEAT1 or mut-NEAT1, and mimics-miR-107 or inhibitor-miR-107 were co-transfected into 293 cells using Lipofectamine 2000 transfection reagent to investigate the interaction between NEAT1 and miR-107. pRL-Tk, wt-CPT1A or mut-CPT1A, and 

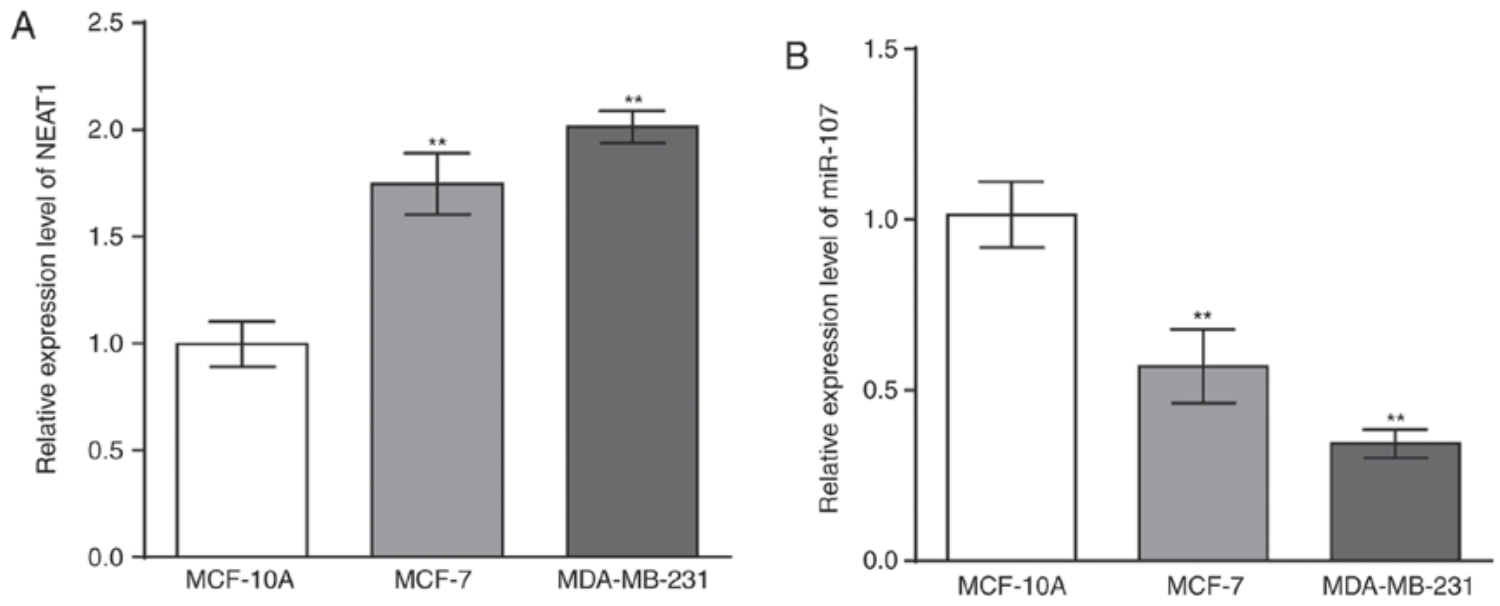

Figure 1. Expression analysis of NEAT1 and miR-107 in breast cancer cells. (A) Expression analysis of NEAT1. NEAT1 is overexpressed in MCF-7 and MDA-MB-231 cells, compared with the expression in normal breast cell MCF-10A cells. (B) Expression analysis of miR-107. miR-107 is expressed at low levels in MCF-7 and MDA-MB-231 cells, compared with the normal breast cell line MCF-10A. Data was obtained from at least three independent experiments. ${ }^{* *} \mathrm{P}<0.01$ vs. MCF-10A. NEAT1, nuclear paraspeckle assembly transcript 1; miR-107, microRNA-107.

mimics-miR-107 or inhibitor-miR-107 were co-transfected into 293 cells to investigate the interaction between CPT1A and miR-107. After $48 \mathrm{~h}$ of transfection, the activity of firefly luciferase, quantified as luminescence, was detected using the Dual-Luciferase Reporter system, and the fluorescence value of Renilla luciferase was set as the internal reference.

Statistics. Data from at least three independent experiments are presented as the mean \pm standard deviation. Statistical analysis was performed using SPSS software 16.0 (SPSS, Inc., Chicago, IL, USA). Statistical significance was measured using Student's t-test or one-way analysis of variance followed by Tukey's post-hoc test. $\mathrm{P}<0.05$ was considered to indicate a statistically significant difference.

\section{Results}

NEAT1 inhibits the expression of miR-107 in BC cells. A total of two BC cell lines, MCF-7 and MDA-MB-231, were selected to analyze the expression levels of NEAT1 and miR-107 as they are commonly used cell lines for the study of BC. MCF-10A cells, a mammary epithelial cell line, was used as the control. The total RNA of these three cell lines was extracted and reverse-transcribed into cDNA. RT-qPCR indicated that NEAT1 expression was significantly increased (Fig. 1A) and that miR-107 expression was significantly decreased in BC cells, compared with the MCF-10A cells (Fig. 1B). To investigate the association between NEAT1 and miR-107 in BC cells, sh-NEAT1 was transfected into MCF-7 and MDA-MB-231 cells to significantly downregulate the expression of NEAT1, compared with the negative control (Fig. 2A). In contrast with NEAT1 expression, miR-107 expression was significantly enhanced in MCF-7 and MDA-MB-231 cells, compared with the negative control (Fig. 2A). In conclusion, NEAT1 inhibits the expression of miR-107 in BC cells.

NEAT1 knockdown inhibits the progression of BC cells. NEAT1-downregulated MCF-7 and MDA-MB-231 cells were cultured for $72 \mathrm{~h}$, and cell proliferation was determined using an MTT assay at $0,24,48,72 \mathrm{~h}$. Accompanied by downregulated NEAT1 and upregulated miR-107, cell proliferation was decreased (Fig. 2B). Subsequently, the effect of NEAT1 on the BC cell cycle was investigated using flow cytometric analysis. Fig. 2C indicates that NEAT1 knockdown significantly promoted apoptosis in $\mathrm{BC}$ cells, compared with the negative control. Compared with the proportion of cells in G1 phase in the negative control that was transfected with sh-NC, the proportion of MCF-7 or MDA-MB-231 cells in G1 phase transfected with sh-NEAT1 was significantly increased (Fig. 2D). The wound healing and Matrigel assays demonstrated that the migratory and invasive abilities of $\mathrm{BC}$ cells were significantly inhibited when NEAT1 was downregulated (Fig. 2E and F). Collectively, NEAT1 knockdown inhibits the proliferation, cell cycle, migration and invasion of BC cells.

NEAT1 knockdown affects tumor development-associated genes in BC cells. To further detect the effect of NEAT1 on the progression of $\mathrm{BC}$ cells, the expression of genes that were associated with the proliferation, cell cycle, migration and invasion of BC cells were determined in sh-NEAT1-transfected MCF-7 and MDA-MB-231 cells. RT-qPCR and western blotting data demonstrated that the mRNA and protein expression levels of apoptotic genes (BAD, CASP9 and COL18A1) were significantly upregulated in sh-NEAT1-transfected BC cells, whereas those of the invasion-associated genes (TIMP-1, PDGF-A and SERPINB2) were significantly downregulated in sh-NEAT1-transfected BC cells (Fig. 3A). The expression of the $\mathrm{BC}$ cell cycle-associated gene cyclin D1 was also significantly downregulated in sh-NEAT1-transfected BC cells, indicating that cells remained at G1 phase. Furthermore, significant downregulation of CDK4 indicated that the cells did not enter the $\mathrm{S}$ division phase (Fig. 3B). Additionally, CPT1A, a novel biomarker of $\mathrm{BC}$, was significantly downregulated at the mRNA and protein levels in sh-NEAT1-transfected BC cells (Fig. 3B).

miR-107 reversely regulates the expression of NEAT1 and negatively regulates the progression of $B C$ cells. To investigate the function of miR-107 in BC cells, mimics-miR-107 

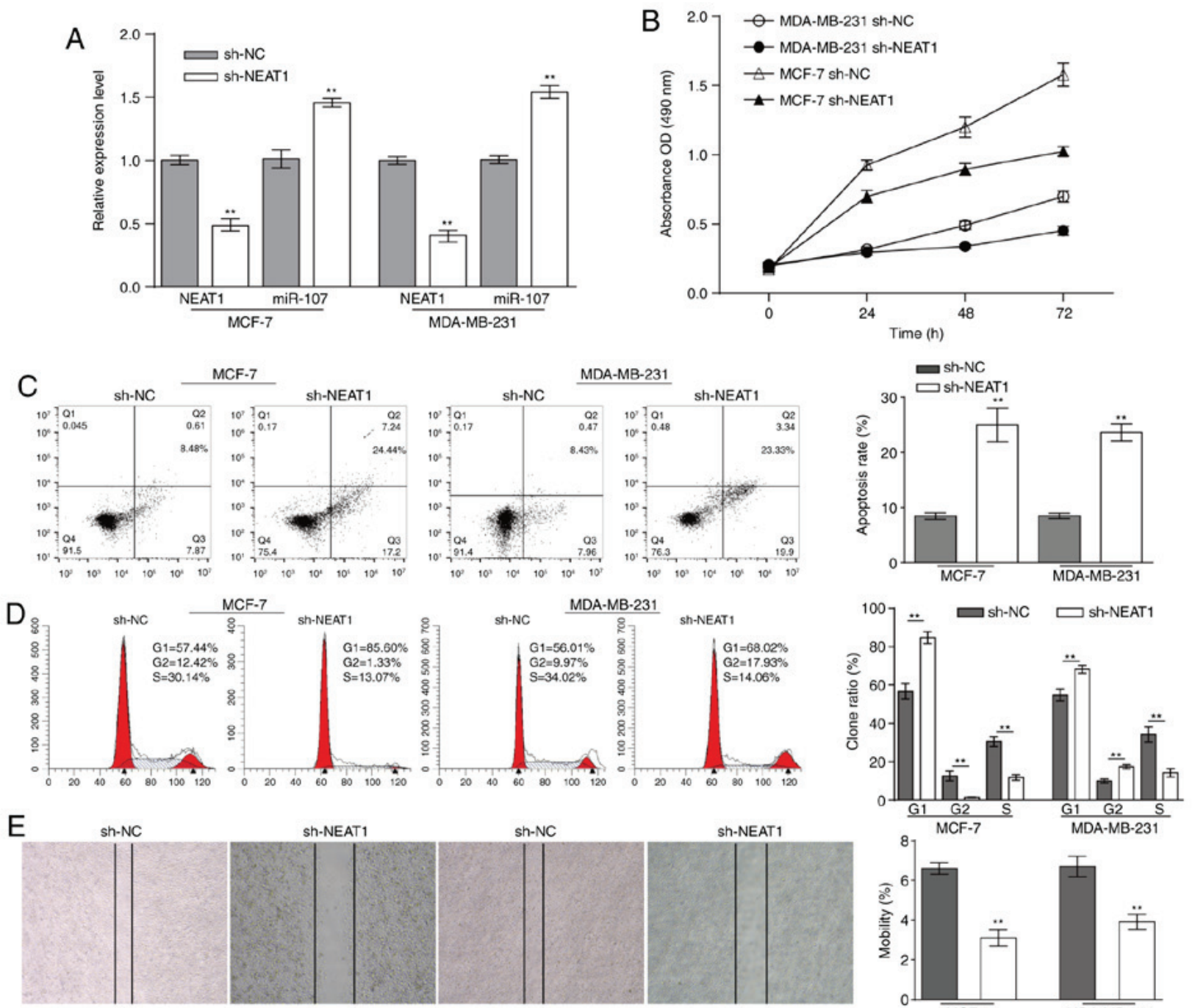

sh-NC

Sh-NEAT1

sh-NC

Sh-NEAT1

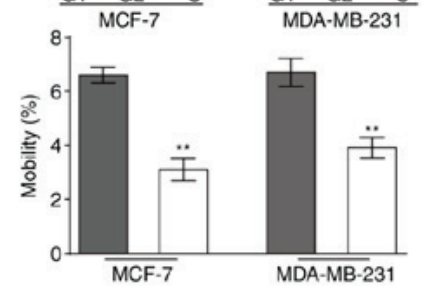

MDA-MB-231
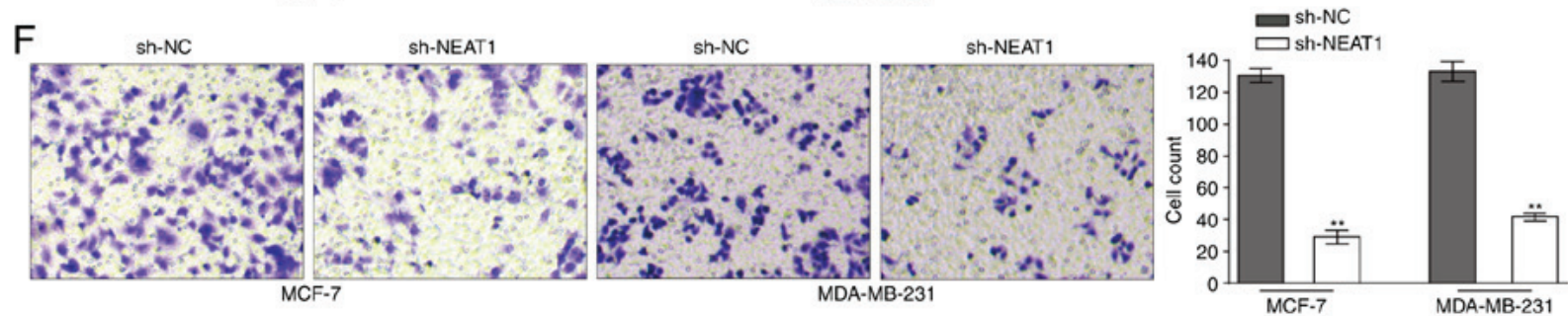

Figure 2. NEAT1 increases the progression of breast cancer cells. (A) Expression analysis of NEAT1 and miR-107 in sh-NEAT1-transfected MCF-7 and MDA-MB-231 cells using the reverse transcription-quantitative polymerase chain reaction. (B) An MTT assay was used to determine the effect of sh-NAET1 on the proliferation of MCF-7 and MDA-MB-231 cells. (C) The apoptotic percentages of MCF-7 and MDA-MB-231 were detected by flow cytometry following NEAT1 knockdown. (D) The cell cycle of MCF-7 and MDA-MB-231 cells was analyzed by flow cytometry following transfection with sh-NEAT1. (E) Migration assays were used to measure the effect of sh-NEAT1 on the cell migration of MCF-7 and MDA-MB-231 (F) Transwell assays were used to determine the effect of sh-NEAT1 on the cell invasion of MCF-7 and MDA-MB-231. Data was obtained from at least three independent experiments. ${ }^{* *} \mathrm{P}<0.01$ vs. sh-NC. NEAT1, nuclear paraspeckle assembly transcript 1; miR-107, microRNA-107; sh-NC, short hairpin-negative control; OD, optical density.

was transfected into MCF-7 and MDA-MB-231 cells to significantly upregulate its expression, and NEAT1 was demonstrated to be significantly downregulated (Fig. 4A). Furthermore, miR-107 was significantly downregulated with the significant overexpression of NEAT1 when MCF-7 and MDA-MB-231 cells were transfected with inhibitor-miR-107 (Fig. 4B). These results indicated that miR-107 can reversely regulate the expression of NEAT1.

The progression of these cells was investigated. Following transfection with mimics-miR-107, an MTT assay revealed that the proliferation rates of MCF-7 and MDA-MB-231 cells were decreased, the rates of apoptosis in $\mathrm{BC}$ cells were increased, and the cell cycle distribution of the majority of the cells remained at G1 phase, compared with the negative control cells. However, when miR-107 was downregulated by inhibitor-miR-107, the proliferation of BC cells was increased, the rates of apoptosis in $\mathrm{BC}$ cells were decreased, and the majority of the cells were not held at G1 phase (Fig. 4C-I). Thus, miR-107 inhibits the proliferation and cell cycle of BC cells. In the migration and invasion experiments, miR-107 

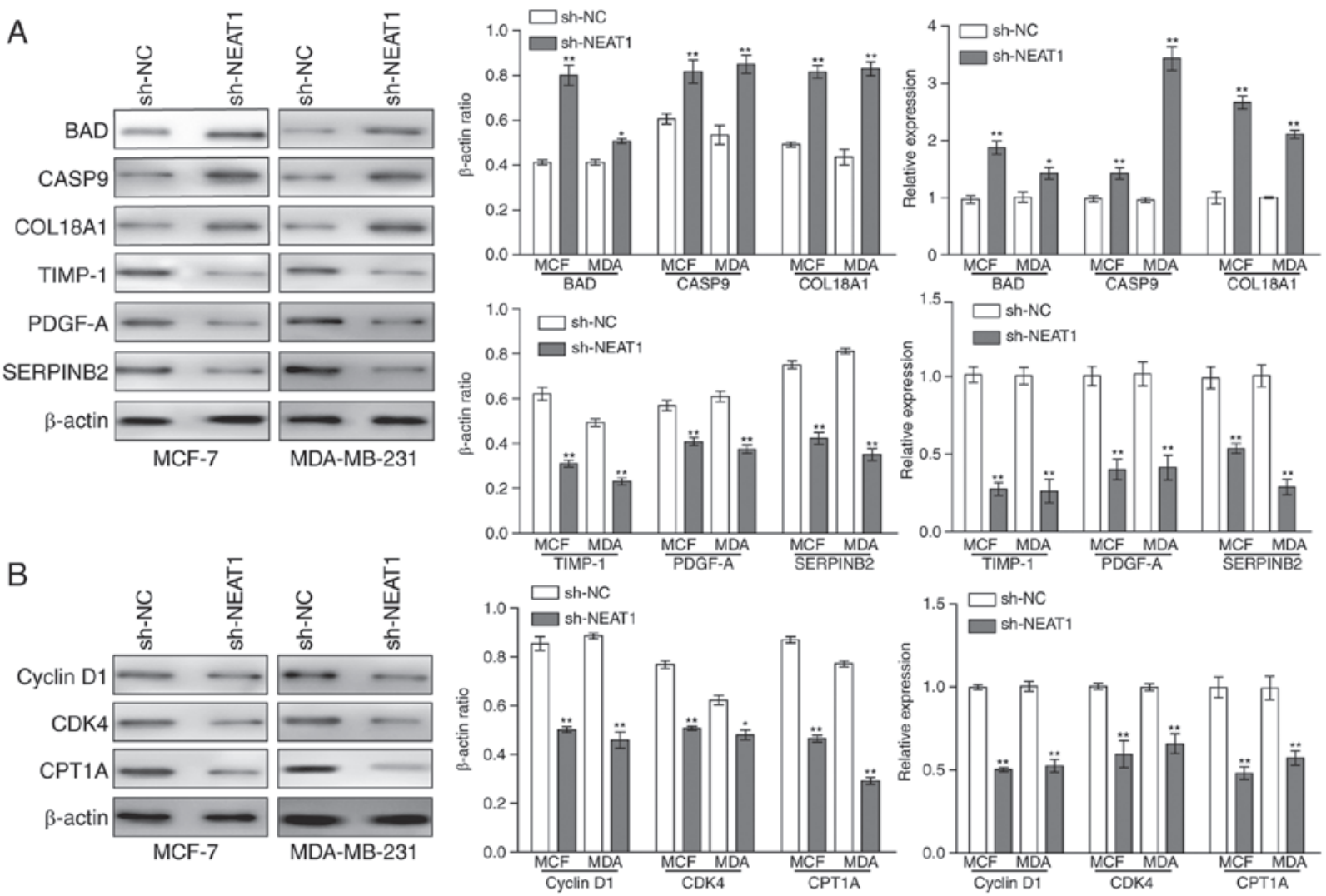

Figure 3. Detection of tumor development-associated genes in NEAT1-knockdown breast cancer cells. (A) Western blot analysis and reverse transcription-quantitative polymerase chain reaction assays were used to determine the protein and mRNA expression levels of BAD, CASP9, COL18A1, TIMP-1, PDGF-A and SERPINB2 in MCF-7 and MDA-MB-231 cells following NEAT1 knockdown. (B) A western blot assay was used to detect the protein expression levels of cyclin D1, CDK4 and CPT1A in MCF-7 and MDA-MB-231 following NEAT1 knockdown. Data was obtained from at least three independent experiments. ${ }^{*} \mathrm{P}<0.05,{ }^{* *} \mathrm{P}<0.01$ vs. sh-NC. BAD, B-cell lymphoma 2-associated agonist of cell death; CASP9, caspase 9; COL18A1, collagen type XVII a 1; TIMP-1, TIMP metallopeptidase inhibitor 1; PDGF-A, platelet-derived growth factor subunit A; SERPINB2, serpin family B member 2; CDK4, cyclin-dependent kinase 4; CPT1A, carnitine palmitoyltransferase-1; NEAT1, nuclear paraspeckle assembly transcript 1; miR-107, microRNA-107; sh-NC, short hairpin-negative control; MCF, MCF-7; MDA, MDA-MB-231.

knockdown significantly promoted the migration and invasion of MCF-7 and MDA-MB-231 cells. By contrast, overexpression of miR-107 significantly inhibited the migration and invasion of these BC cells (Fig. 4J and K). In summary, miR-107 negatively regulates the progression of $\mathrm{BC}$ cells.

miR-107 regulates the progression of BC cells through tumor development-associated genes. To identify how miR-107 negatively regulates the progression of BC cells, the expression of tumor development-associated genes was detected in mimics-miR-107 or inhibitor-miR-107-transfected BC cells. To determine the $\beta$-actin ratio and relative expression of each protein and gene, western blotting and RT-qPCR were used. With the upregulation of miR-107 by mimics-miR-107, the expression levels of apoptosis-associated genes BAD, CASP9 and COL18A1 were significantly increased, whereas the expression levels of invasion-associated genes TIMP-1, PDGF-A and SERPINB2 were significantly decreased (Fig. 5A). Consistent with the flow cytometry results, cyclin D1 and CDK4, which regulate the cell cycle, were significantly downregulated. CPT1A was also significantly downregulated (Fig. 5B). The identical analysis was performed on miR-107-knockdown MCF-7 and MDA-MB-231 cells that were transfected with inhibitor-miR-107. In contrast with the aforementioned results, the expression levels of BAD, CASP9 and COL18A1 were significantly decreased (Fig. 5C), and the expression levels of TIMP-1, PDGF-A, SERPINB2, cyclin D1, CDK4 and CPA1A were significantly increased (Fig. 5C and D). Collectively, these results indicate that miR-107 regulates the progression of $\mathrm{BC}$ cells through tumor development-associated genes.

miR-107 regulates the expression of NEAT1 and CPT1A by direct targeting. As aforementioned, NEAT1 negatively regulates the expression of $\mathrm{miR}-107$, and $\mathrm{miR}-107$ inhibits the downstream gene CPT1A. Additionally, miR-107 feedback regulates the expression of NEAT1. The binding sites of NEAT1 and CPT1A on miR-107 were predicted (Fig. 6A). To investigate the regulatory mechanism between miR-107 and NEAT1 or CPT1A, wt-NEAT1, mut-NEAT1, wt-CPT1A and mut-CPT1A luciferase reporter vectors were constructed. wt-NEAT1 and mimics-miR-107 or inhibitor-miR-107 were co-transfected into 293 cells. The activity of luciferase was significantly increased in the miR-107-downregulated 293 cells, compared with the negative control (Fig. 6B). Conversely, in miR-107-upregulated 293 cells, the activity of luciferase was significantly decreased, compared with the negative control (Fig. 6B). However, in the 
A

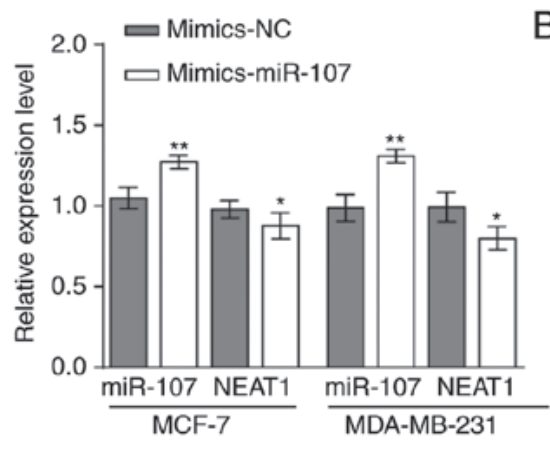

C

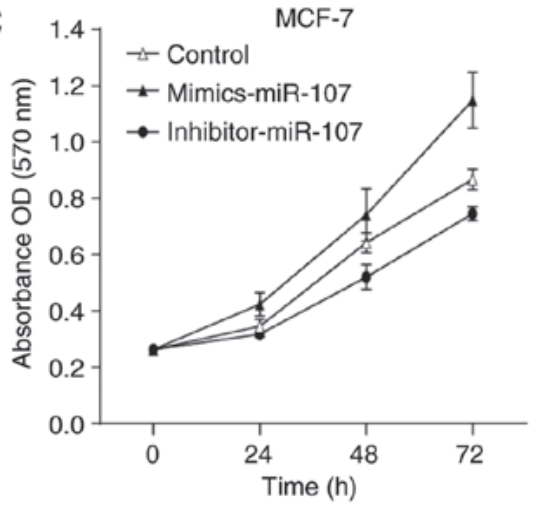

B
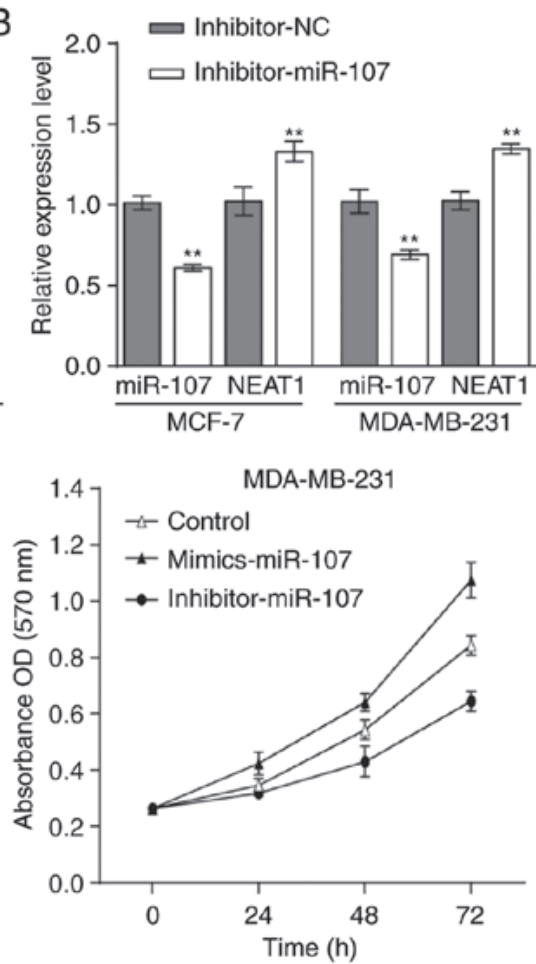

$\mathrm{D}$

MCF-7
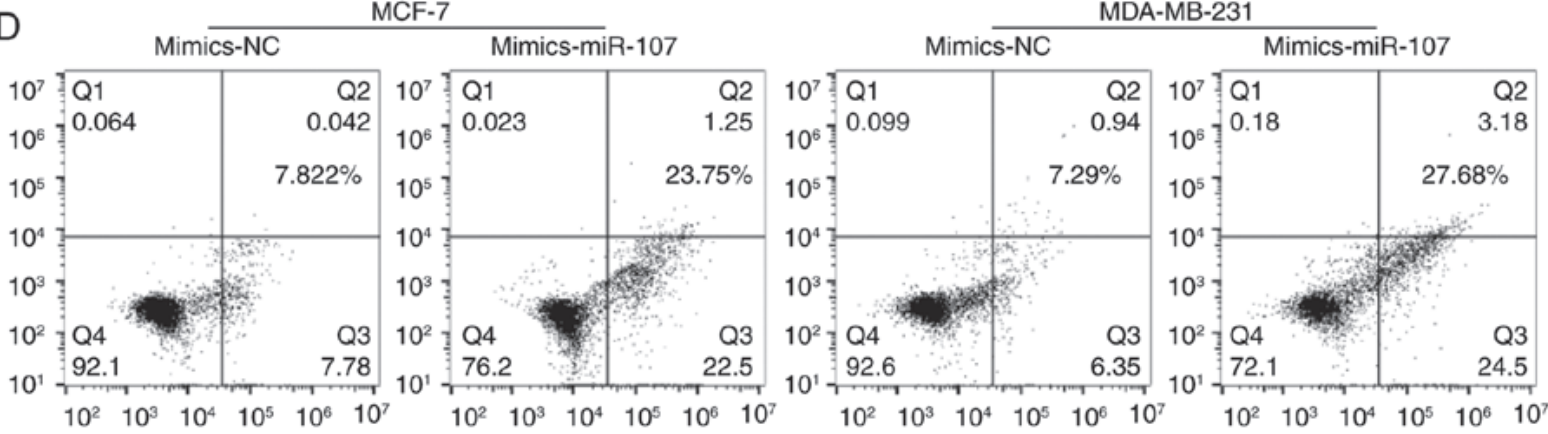

\section{$\mathrm{E}$}

MCF-7
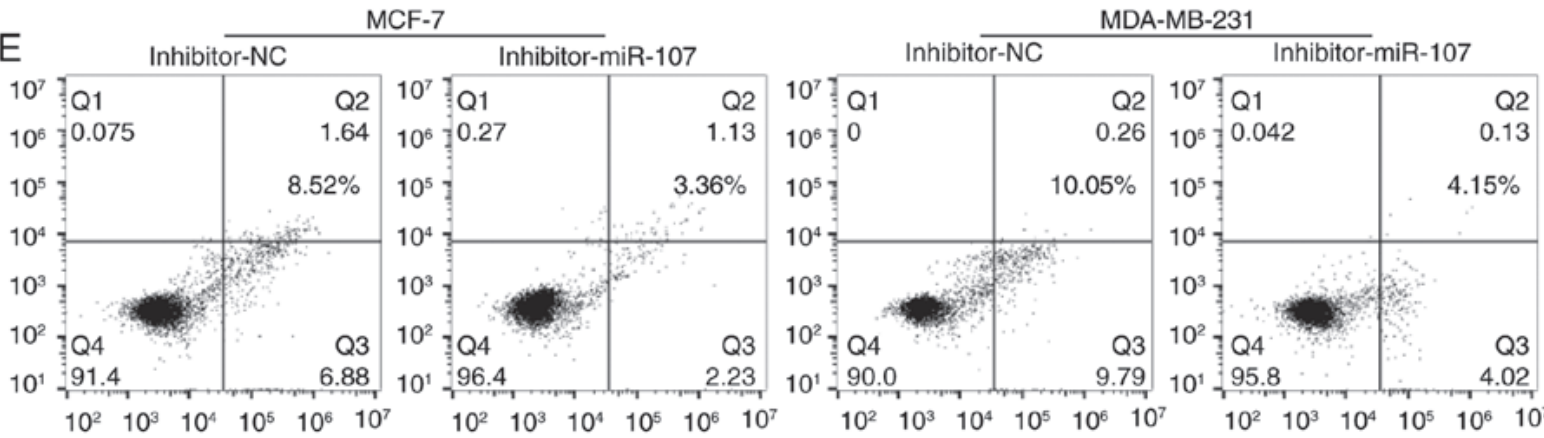

Figure 4. NEAT1 negatively regulates the progression of breast cancer cells. A reverse transcription-quantitative polymerase chain reaction assay was used to determine the level of NEAT1 and miR-107 in MCF-7 and MDA-MB-231 cells that were transfected with (A) mimics-miR-107 or mimics-NC and (B) inhibitor-miR-107 or inhibitor-NC. **P<0.01 vs. respective NC. (C) Proliferation of MCF-7 and MDA-MB-231 cells that were transfected with mimics-miR-107 or inhibitor-miR-107, as detected with an MTT assay. The apoptotic percentages of MCF-7 and MDA-MB-231 transfected with (D) mimics-miR-107 or mimics-NC and (E) inhibitor-miR-107 or inhibitor-NC were analyzed with flow cytometry. (F) The quantification of apoptotic percentages. "P<0.05 and ${ }^{* *} \mathrm{P}<0.01$ vs. mimics-NC; $\mathrm{P}<0.05$ and ${ }^{\# \#} \mathrm{P}<0.01$ vs. inhibitor-NC.

mut-NEAT1 groups, there were no significant changes in luciferase activity in the miR-107-overexpression and the miR-107-knockdown 293 cells (Fig. 6B). Similar results were observed for CPT1A (Fig. 6C). The expression levels of CPT1A and NEAT1 were significantly downregulated by mimics-miR-107, and transfection with pcDNA3.1-NEAT1 rescued the inhibitory effect of mimics-miR-107 on MCF-7 cells, with the expression level of miR-107 presenting the opposite trend (Fig. 6D and E). These results indicated that miR-107 can target NEAT1 and CPT1A directly to regulate their expression. Therefore, NEAT1 and CPT1A can compete in conjunction with miR-107. 
G
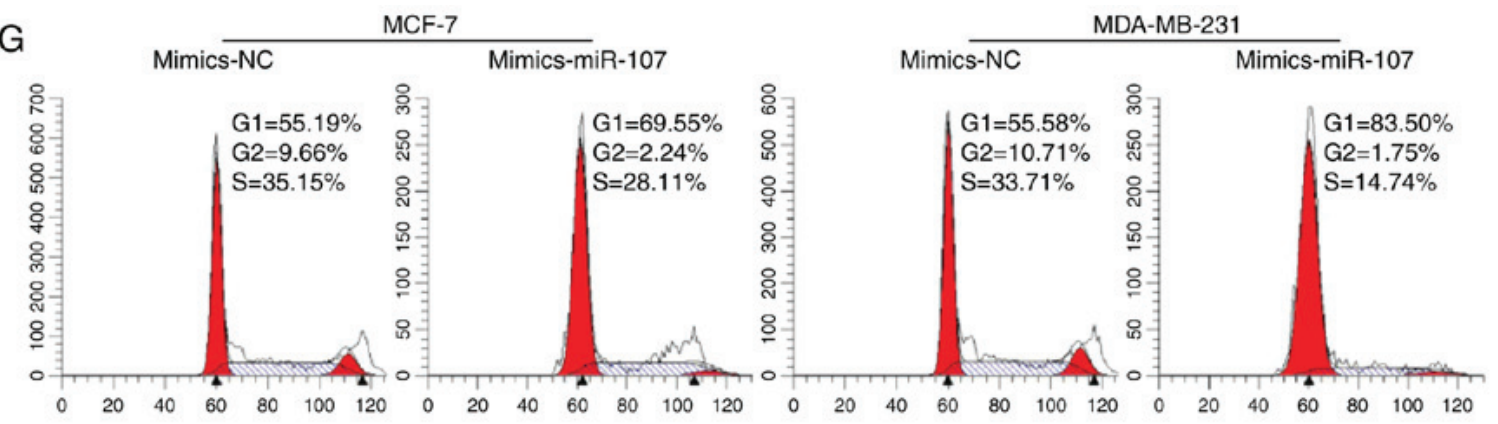

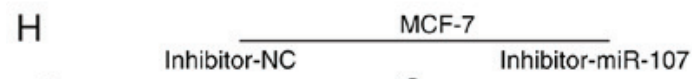
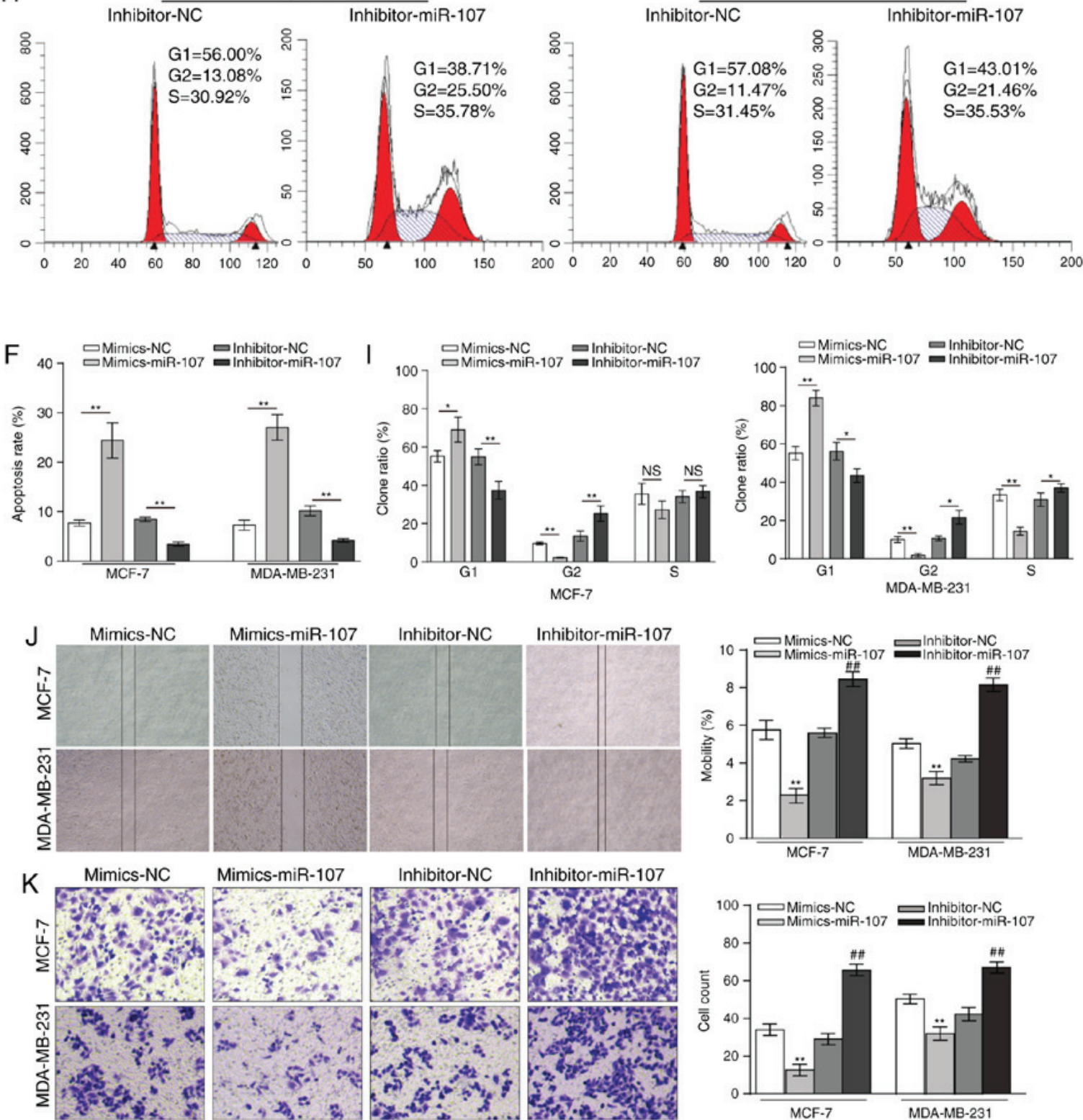

Figure 4. Continued. NEAT1 negatively regulates the progression of breast cancer cells. The cell cycle distribution of MCF-7 and MDA-MB-231 transfected with (G) mimics-miR-107 or mimics-NC and (H) inhibitor-miR-107 or inhibitor-NC were analyzed with flow cytometry. (I) The quantification of cell cycle distribution. ${ }^{*} \mathrm{P}<0.05$ and ${ }^{* *} \mathrm{P}<0.01$ as indicated. (J) Wound healing analyses and $(\mathrm{K})$ Transwell invasion analyses of MCF-7 and MDA-MB-231, which were transfected with mimics-miR-107, mimics-NC, inhibitor-miR-107 or inhibitor-NC. ${ }^{*}<0.05$ and ${ }^{* *} \mathrm{P}<0.01$ vs. mimics-NC; ${ }^{\#} \mathrm{P}<0.05$ and ${ }^{\# \#} \mathrm{P}<0.01$ vs. inhibitor-NC. NEAT1, nuclear paraspeckle assembly transcript 1; miR-107, microRNA-107; NC, negative control; ns, no significance; OD, optical density.

\section{Discussion}

LncRNAs are a class of transcription factors with a length
$>200$ bp that do not encode proteins, but regulate the expression levels of genes at various levels in the form of RNA (35). Studies have demonstrated that lncRNA is associated with 

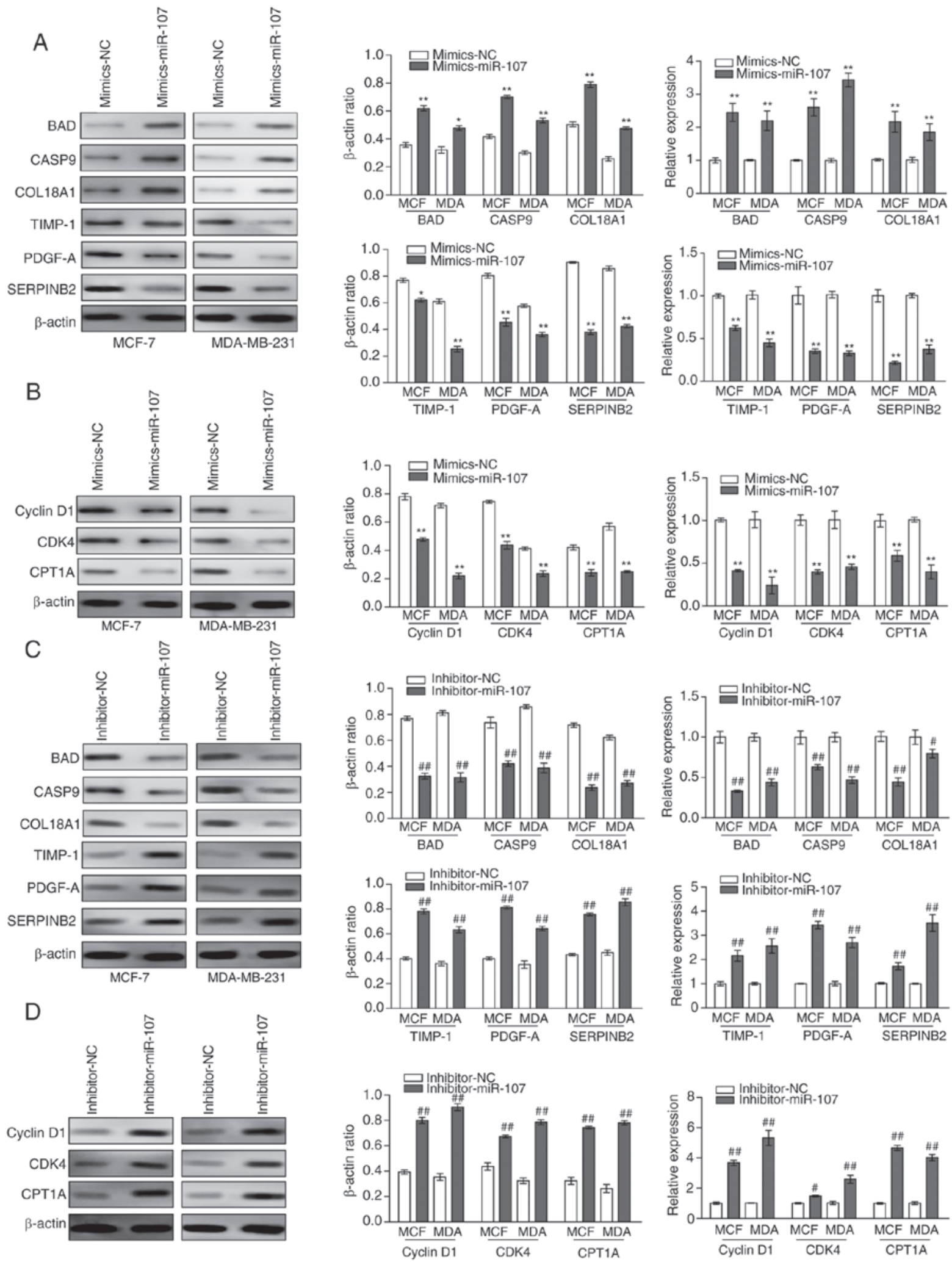

Figure 5. Detection of tumor development-associated genes in miR-107 increased or decreased breast cancer cells. The western blot lanes were translated into corresponding greyscale values to present the $\beta$-actin ratio and relative expression of each protein. (A) Western blot analysis and RT-qPCR assays were used to determine the protein and mRNA expression levels of BAD, CASP9, COL18A1, TIMP-1, PDGF-A and SERPINB2 in MCF-7 and MDA-MB-231 cells that were transfected with mimics-miR-107. (B) Western blot analysis and RT-qPCR assays were used to detect the levels of cyclin D1, CDK4 and CPT1A. (C) Western blot analysis and RT-qPCR assays were used to determine the protein and mRNA expression levels of BAD, CASP9, COL18A1, TIMP-1, PDGF-A and SERPINB2 in MCF-7 and MDA-MB-231 cells that were transfected with inhibitor-miR-107. (D) Western blot analysis and RT-qPCR assays were used to determine the protein and mRNA expression levels of cyclin D1, CDK4 and CPT1A in MCF-7 and MDA-MB-231 cells that were transfected with inhibitor-miR-107. Data was obtained from at least three independent experiments. ${ }^{*} \mathrm{P}<0.05$ and ${ }^{* *} \mathrm{P}<0.01$ vs. mimics-NC; ${ }^{*} \mathrm{P}<0.05$ and ${ }^{\# \#} \mathrm{P}<0.01$ vs. inhibitor-NC. RT-qPCR, reverse transcription-quantitative polymerase chain reaction; BAD, B-cell lymphoma 2-associated agonist of cell death; CASP9, caspase 9; COL18A1, collagen type XVII a 1; TIMP-1, TIMP metallopeptidase inhibitor 1; PDGF-A, platelet-derived growth factor subunit A; SERPINB2, serpin family B member 2; CDK4, cyclin-dependent kinase 4; CPT1A, carnitine palmitoyltransferase-1; NEAT1, nuclear paraspeckle assembly transcript 1; miR-107, microRNA-107; NC, negative control. 


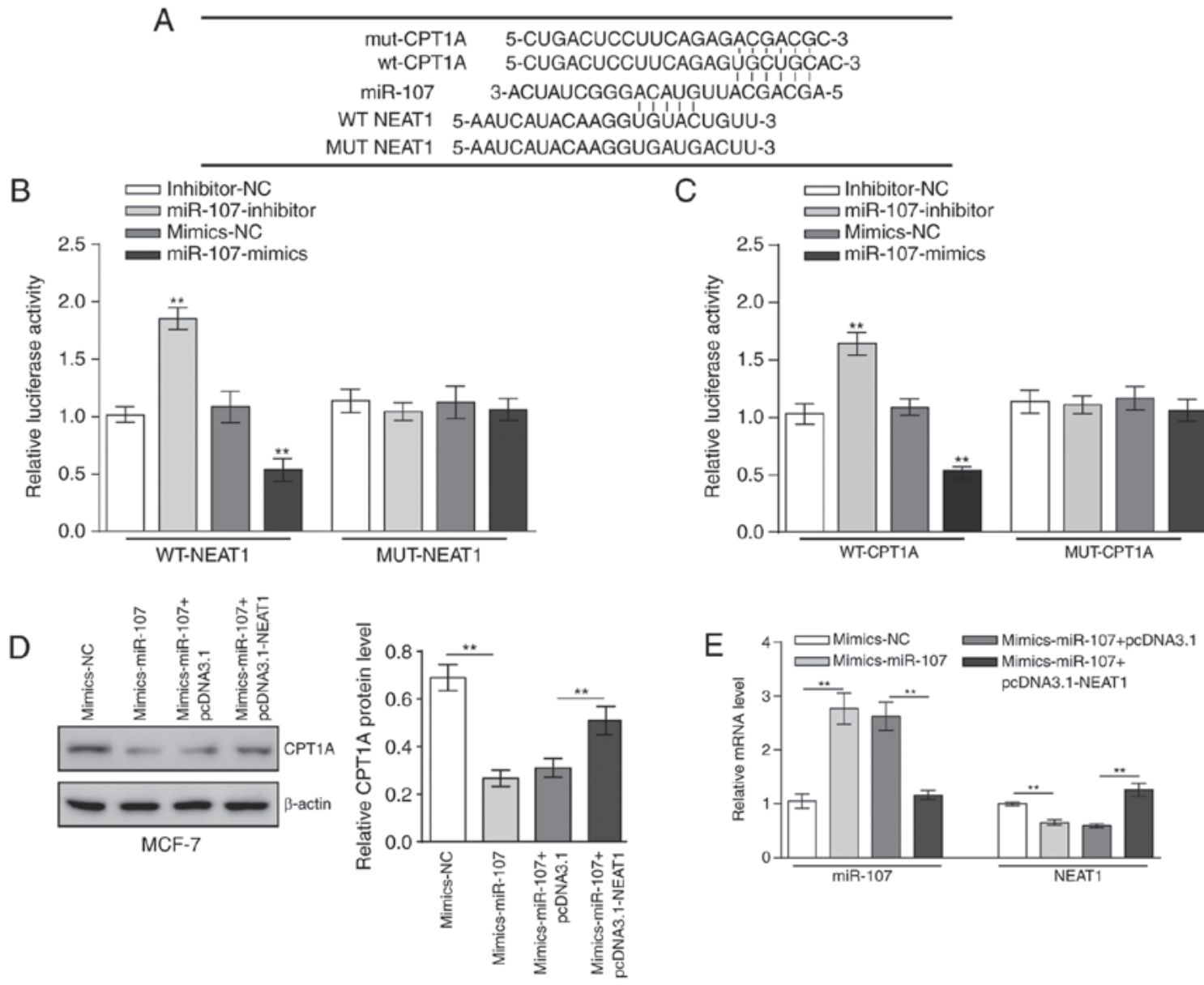

Figure 6. miR-107 regulates the expression of NEAT1 and CPT1A by direct targeting. (A) The binding sites of NEAT1 and CPT1A on miR-107 were predicted. (B) Relative luciferase activity was measured following 293 cells being transfected with wt-NEAT1 or mut-NEAT1. (C) Relative luciferase activity was measured following 293 cells being transfected with wt-CPT1A or mut-CPT1A. (D) Western blot analysis was used to detect the expression of CPT1A, NEAT1 and miR-107 following miR-107 overexpression or miR-107 and NEAT1 overexpression. (E) Reverse transcription-quantitative polymerase chain reaction assays were used to detect the mRNA level of CPT1A, NEAT1 and miR-107 following miR-107 overexpression or miR-107 and NEAT1 overexpression. Data was obtained from at least three independent experiments. " $\mathrm{P}<0.01$. CPT1A, carnitine palmitoyltransferase-1; NEAT1, nuclear paraspeckle assembly transcript 1; miR-107, microRNA-107; NC, negative control; wt, wild-type; mut, mutated.

cancer, and the expression of lncRNA in normal tissues and corresponding tumor tissues demonstrated significant differences $(21,23,24)$. Abnormal lncRNA expression serves a substantial function in tumor progression and can be a predictor of tumor progression (36); however, the function of lncRNAs in BC is not well-characterized.

The IncRNA NEAT1 has been reported to be upregulated in various tumor types. High levels of NEAT1 were significantly associated with clinicopathological features of hepatocellular carcinoma (37). Additionally, upregulated NEAT1 was associated with aggressive prostate cancer (38). In BC, a previous study indicated that the expression of NEAT1 was increased significantly under hypoxia and promoted the proliferation of BC cells (18). In the present study, it was affirmed that NEAT1 was overexpressed in MCF-7 and MDA-MB-231 cells. Furthermore, the knockdown of NEAT1 by sh-NEAT1 resulted in the inhibition of proliferation, cell cycle, migration and invasion of BC cells. Additionally, the apoptotic genes BAD, CASP9 and COL18A were upregulated, but the invasion-associated genes TIMP-1, PDGF-A, SERPINB2 and cell cycle-associated genes cyclin D1 and CDK4 were downregulated. However, the mechanism by which NEAT1 affects $\mathrm{BC}$ remains unclear.

The disorder of lipid metabolism can induce the development of a number of tumor types, such as glioma and breast cancer. Enhancing the expression of CPT1A in BC cells, which can promote the oxidation of fatty acids and decrease its accumulation, can significantly improve BC symptoms (39). In the present study, it was identified that NEAT1 could promote the progression of $\mathrm{BC}$ by regulating its proliferation. NEAT1 knockdown downregulated the expression of CPT1A and inhibits the development of $\mathrm{BC}$ cells.

In recent years, an increasing number of studies have focused on miRNA, and a normal expression of miRNA requires a balanced physiological environment (40). These miRNAs, such as miR-15 and miR-16, participate in the majority of genetic pathways, including cell cycle checkpoint, cell proliferation and apoptosis (40). Deregulation of miRNA expression causes widespread changes in gene expression and is associated with various cancer types, such as lung cancer and pancreatic cancer (40). miR-107 has been reported to be a tumor suppressor molecule in numerous cancer types, such as BC, glioma and cervical cancer $(20,21)$. The results of 
the present study indicated that the upregulation of miR-107 inhibited the proliferation and migration of BC cells and the expression of CPT1A. However, the knockdown of miR-107 promoted the proliferation and invasion of $\mathrm{BC}$ cells, and the expression of CPT1A was increased. These results indicated that miR-107 negatively regulates CPT1A.

Emerging evidence has revealed the association of the interaction between IncRNAs and miRNAs, and cancer metastasis $(41,42)$. miRNA can negatively regulate lncRNA by a mechanism similar to that of mRNA (43) or positively regulate lncRNA through epigenetic regulation (44). lncRNA can competitively combine with the miRNA to inhibit the negative regulation of the miRNA on target genes indirectly (45). Another regulatory mechanism between lncRNA and miRNA is that lncRNA acts as competing endogenous RNA to suppress miRNA expression by acting as a miRNA sponge (46). Additionally, lncRNA acts as a potential primary miRNA to produce mature miRNA, thereby indirectly regulating the expression of target genes (47). In the present study, two different combined sites on miR-107 that exhibited reverse complementarity to NEAT1 and CPT1A separately were predicted. Luciferase assays demonstrated that NEAT1 and CPT1A could bind to miR-107. These results indicated that NEAT1 and CPT1A could compete in combination with miR-107.

In summary, downregulation of NEAT1 result in decreased expression of miR-107 and increased expression of CPT1A. Furthermore, miR-107 knockdown triggers the upregulation of NEAT1 and CPT1A. Combined with the results of proliferation experiments of $\mathrm{BC}$ cells and luciferase assays, a potential regulation mechanism involving NEAT1, miR-107 and CPT1A in BC cells, in which miR-107 inhibits the expression of CPT1A and NEAT1 downregulates the expression of miR-107 through the competitive combination of miR-107 and CPT1A, were determined. Thus, NEAT1 promotes the expression of CPT1A by inhibiting miR-107 to improve the progression of $\mathrm{BC}$ cells.

\section{Acknowledgements}

Not applicable.

\section{Funding}

No funding received.

\section{Availability of data and materials}

The datasets used and analyzed during the current study are available from the corresponding author on reasonable request.

\section{Authors' contributions}

YX designed the study and prepared the manuscript. ZeL did literature research and performed experimental studies. ZhL and SW analyzed the data and statistics. NS performed the experimental studies. YX acquired and analyzed the data. TH made substantial contributions to the conception of the work, edited and reviewed the manuscript, and agreed to be accountable for all aspects of the work in ensuring that questions related to the accuracy. All authors read and approved the final manuscript.

\section{Ethics approval and consent to participate}

Not applicable.

\section{Patient consent for publication}

Not applicable.

\section{Competing interests}

The authors declare that they have no competing interests.

\section{References}

1. DeSantis C, Ma J, Bryan L and Jemal A: Breast cancer statistics, 2013. CA Cancer J Clin 64: 52-62, 2014

2. Chen W, Chen W, Zheng R, Baade PD, Zhang S, Zeng H, Bray F, Jemal A, Yu XQ and He J: Cancer statistics in China, 2015. CA Cancer J Clin 66: 115-132, 2016.

3. Siegel RL, Miller KD and Jemal A: Cancer statistics, 2016. CA Cancer J Clin 66: 7-30, 2016

4. Samuel SM, Varghese E, Varghese S and Büsselberg D: Challenges and perspectives in the treatment of diabetes associated breast cancer. Cancer Treat Rev 70: 98-111, 2018.

5. Malhotra A, Jain M, Prakash H, Vasquez KM and Jain A: The regulatory roles of long non-coding RNAs in the development of chemoresistance in breast cancer. Oncotarget 8: 110671-110684, 2017.

6. Mercer TR, Dinger ME and Mattick JS: Long non-coding RNAs: Insights into functions. Nat Revi Genet 10: 155-159, 2009.

7. Costa FF, Non-coding RNAs: New players in eukaryotic biology. Gene 357: 83-94, 2005.

8. Shi XF, Sun M, Liu H, Yao Y and Song Y: Long non-coding RNAs: A new frontier in the study of human diseases. Cancer Lett 339: 159-166, 2013.

9. Zhang Z, Li Z, Li Y and Zang A: MicroRNA and signaling pathways in gastric cancer. Cancer Gene Ther 21: 305-316, 2014.

10. Gibb EA, Vucic EA, Enfield KS, Stewart GL, Lonergan KM, Kennett JY, Becker-Santos DD, MacAulay CE, Lam S, Brown CJ and Lam WL: Human cancer long non-coding RNA transcriptomes. PLoS One 6: e25915, 2011.

11. Ke H, Zhao L, Feng X, Xu H, Zou L, Yang Q, Su X, Peng L and Jiao B: NEAT1 is required for survival of breast cancer cells through FUS and miR-548. Gene Regul Syst Bio 10 (Suppl 1): S11-S17, 2016.

12. Jiang X, Zhou Y, Sun AJ and Xue JL: NEAT1 contributes to breast cancer progression through modulating miR-448 and ZEB1. J Cell Physiol 233: 8558-8566, 2018.

13. Clemson CM, Hutchinson JN, Sara SA, Ensminger AW, Fox AH, Chess A and Lawrence JB: An architectural role for a nuclear noncoding RNA: NEAT1 RNA is essential for the structure of paraspeckles. Mol Cell 33: 717-726, 2009.

14. Souquere S, Beauclair G, Harper F, Fox A and Pierron G: Highly ordered spatial organization of the structural long noncoding NEAT1 RNAs within paraspeckle nuclear bodies. Mol Biol Cell 21: 4020-4027, 2010.

15. Iseli C, Stevenson BJ, de Souza SJ, Samaia HB, Camargo AA, Buetow KH, Strausberg RL, Simpson AJ, Bucher P and Jongeneel CV: Long-range heterogeneity at the 3 'ends of human mRNAs. Genome Res 12: 1068-1074, 2002.

16. Chen LL and Carmichael GG: Gene regulation by SINES and inosines Biological consequences of A-to-I editing of Alu element inverted repeats. Cell Cycle 7: 3294-3301, 2008.

17. Choudhry H, Schödel J, Oikonomopoulos S, Camps C, Grampp S, Harris AL, Ratcliffe PJ, Ragoussis J and Mole DR: Extensive regulation of the non-coding transcriptome by hypoxia: Role of HIF in releasing paused RNApol2. EMBO Rep 15: 70-76, 2014.

18. Choudhry H, Albukhari A, Morotti M, Haider S, Moralli D, Smythies J, Schödel J, Green CM, Camps C, Buffa F et al: Tumor hypoxia induces nuclear paraspeckle formation through HIF- $2 \alpha$ dependent transcriptional activation of NEAT1 leading to cancer cell survival 34: 4482-4490, 2015. 
19. Curtis C, Shah SP, Chin SF, Turashvili G, Rueda OM,Dunning MJ, Speed D, Lynch AG, Samarajiwa S, Yuan Y, et al: The genomic and transcriptomic architecture of 2,000 breast tumours reveals novel subgroups. Nature 486: 346-352, 2012.

20. Yang XL, Xiao Z, Du X, Huang L and Du G: Silencing of the long non-coding RNA NEAT1 suppresses glioma stem-like properties through modulation of the miR-107/CDK6 pathway. Oncol Rep 37: 555-562, 2017.

21. Wan P, Wu T, Zhou H, Jin Q, He G, Yu H, Xuan L, Wang X, Tian L, Sun Y, et al: Long noncoding RNA NEAT1 promotes laryngeal squamous cell cancer through regulating miR-107/CDK6 pathway. J Exp Clin Cancer Res 35: 22, 2016.

22. Lee KH, Lotterman C, Karikari C, Omura N, Feldmann G, Habbe N, Goggins MG, Mendell JT and Maitra A: Epigenetic silencing of MicroRNA miR-107 regulates cyclin-dependent kinase 6 expression in pancreatic cancer. Pancreatology 9: 293-301, 2009

23. Davidson LA, Wang N, Shah MS, Lupton JR, Ivanov I and Chapkin RS: n-3 Polyunsaturated fatty acids modulate carcinogen-directed non-coding microRNA signatures in rat colon. Carcinogenesis 30: 2077-2084, 2009.

24. Li XY, Luo QF, Wei CK, Li DF, Li J and Fang L: MiRNA-107 inhibits proliferation and migration by targeting CDK8 in breast cancer. Int J Clin Exp Med 7: 32-40, 2014.

25. Fritz IB and Yue KT: Long-chain carnitine acyltransferase and the role of acylcarnitine derivatives in the catalytic increase of fatty acid oxidation induced by carnitine. J Lipid Res 4: 279-288, 1963.

26. Britton $\mathrm{CH}$, Schultz RA, Zhang B, Esser V, Foster DW and McGarry JD: Human liver mitochondrial carnitine palmitoyltransferase I: Characterization of its cDNA and chromosomal localization and partial analysis of the gene. Proc Natl Acad Sci USA 92: 1984-1988, 1995.

27. McGarry JD and Brown NF: The mitochondrial carnitine palmitoyltransferase system. From concept to molecular analysis. Eur J Biochem 244: 1-14, 1997.

28. Swierczynski J, Hebanowska A and Sledzinski T: Role of abnormal lipid metabolism in development, progression, diagnosis and therapy of pancreatic cancer. World J Gastroenterol 20 : 2279-2303, 2014.

29. Kroemer G and Pouyssegur J: Tumor cell metabolism: cancer's Achilles' heel. Cancer Cell 13: 472-482, 2008.

30. Lin H, Lu JP, Laflamme P, Qiao S, Shayegan B, Bryskin I, Monardo L, Wilson BC, Singh G and Pinthus JH: Inter-related in vitro effects of androgens, fatty acids and oxidative stress in prostate cancer: A mechanistic model supporting prevention strategies. Int J Oncol 37: 761-766, 2010.

31. Pucci S, Zonetti MJ, Fisco T, Polidoro C, Bocchinfuso G, Palleschi A, Novelli G, Spagnoli LG and Mazzarelli P: Carnitine palmitoyl transferase-1A (CPT1A): A new tumor specific target in human breast cancer. Oncotarget 7: 19982-19996, 2016.

32. Trajkovski M, Hausser J, Soutschek J, Bhat B, Akin A, Zavolan M, Heim MH and Stoffel M: MicroRNAs 103 and 107 regulate insulin sensitivity. Nature 474: 649-653, 2011.

33. Bhatia H, Pattnaik BR and Datta M: Inhibition of mitochondrial $\beta$-oxidation by miR-107 promotes hepatic lipid accumulation and impairs glucose tolerance in vivo. Int J Obes (Lond) 40: 861-869, 2016.
34. Livak KJ and Schmittgen TD: Analysis of relative gene expression data using real-time quantitative PCR and the 2(-Delta Delta C(T)) method. Methods 25: 402-408, 2001.

35. Caley DP, Pink RC, Trujillano D and Carter DR: Long noncoding RNAs, chromatin, and development. ScientificWorldJournal 10: 90-102, 2010.

36. Gibb EA, Enfield KS, Stewart GL, Lonergan KM, Chari R, Ng RT, Zhang L, MacAulay CE, Rosin MP and Lam WL: Long non-coding RNAs are expressed in oral mucosa and altered in oral premalignant lesions. Oral Oncol 47: 1055-1061, 2011.

37. Guo S, Chen W, Luo Y, Ren F, Zhong T, Rong M, Dang Y, Feng $\mathrm{Z}$ and Chen G: Clinical implication of long non-coding RNA NEAT1 expression in hepatocellular carcinoma patients. Int J Clin Exp Pathol 8: 5395-5402, 2015.

38. Chakravarty D, Sboner A, Nair SS, Giannopoulou E, Li R, Hennig S, Mosquera JM, Pauwels J, Park K, Kossai M, et al: The oestrogen receptor alpha-regulated lncRNA NEAT1 is a critical modulator of prostate cancer. Nat Commun 5: 5383, 2014

39. Linher-Melville K, Zantinge S, Sanli T, Gerstein H, Tsakiridis T and Singh G: Establishing a relationship between prolactin and altered fatty acid $\beta$-Oxidation via carnitine palmitoyl transferase 1 in breast cancer cells. BMC Cancer 11: 56, 2011.

40. Mishra S, Yadav T and Rani V: Exploring miRNA based approaches in cancer diagnostics and therapeutics. Crit Rev Oncol Hematol 98: 12-23, 2016.

41. Wu Q, Guo L, Jiang F, Li L, Li Z and Chen F: Analysis of the miRNA-mRNA-lncRNA networks in ER plus and ER-breast cancer cell lines. J Cell Mol Med 19: 2874-2887, 2015.

42. Ye S, Yang L, Zhao X, Song W, Wang W and Zheng S: Bioinformatics method to predict two regulation mechanism: TF-miRNA-mRNA and lncRNA-miRNA-mRNA in Pancreatic Cancer. Cell Biochem Biophys 70: 1849-1858, 2014.

43. Chiyomaru T, Fukuhara S, Saini S, Majid S, Deng G, Shahryari V, Chang I, Tanaka Y, Enokida H, Nakagawa M, et al: Long Non-coding RNA HOTAIR is targeted and regulated by miR-141 in human cancer cells. J Biol Chem 289: 12550-12565, 2014.

44. Braconi C, Kogure T, Valeri N, Huang N, Nuovo G, Costinean S, Negrini M, Miotto E, Croce CM and Patel T: microRNA-29 can regulate expression of the long non-coding RNA gene MEG3 in hepatocellular cancer. Oncogene 30: 4750-4756, 2011

45. Faghihi MA, Modarresi F, Khalil AM, Wood DE, Sahagan BG, Morgan TE, Finch CE, St Laurent G III, Kenny PJ and Wahlestedt C: Expression of a noncoding RNA is elevated in Alzheimer's disease and drives rapid feed-forward regulation of beta-secretase. Nat Med 14: 723-730, 2008.

46. Salmena L, Poliseno L, Tay Y, Kats L and Pandolfi PP: A ceRNA Hypothesis: The Rosetta stone of a hidden RNA language? Cell 146: 353-358, 2011

47. Keniry A, Oxley D, Monnier P, Kyba M, Dandolo L, Smits G and Reik W: The H19 lincRNA is a developmental reservoir of miR-675 that suppresses growth and lgf1r. Nat Cell Biol 14: 659-665, 2012. 